\title{
O FENÔMENO "RECLAME AQUI" À LUZ DA ANTROPOLOGIA JURÍDICA: UM EXEMPLO DE PLURALISMO JURÍDICO
}

\author{
Marcelo Tadeu Nascimento* \\ Marco Antonio Barbosa**
}

\begin{abstract}
SUMÁRIO: Introdução; 2 Internet e as alterações nas relações de consumo: do direito estatal ao direito comunitário; 3 O fenômeno Reclame Aqui à luz da contemporânea antropologia jurídica e os direitos consumeristas; 4 Concepção Antropológica de Pluralismo Jurídico; 5 O Direito na Sociedade da Informação; 6 Considerações Finais; Referências.
\end{abstract}

RESUMO: O presente trabalho propõe abordar o fenômeno Reclame Aqui, canal digital por meio do qual fornecedores e consumidores dialogam sobre impasses e resolvem seus conflitos (direitos consumeristas). O método é a revisão bibliográfica e a análise direta da funcionalidade do referido site. Desse modo, verificar a possibilidade de enquadramento desse canal digital na perspectiva dos sistemas mistos de Direito, conforme a definição da Antropologia Jurídica contemporânea a qual sustenta que em um campo social determinado é possível identificar comportamentos ligados a mais de um sistema jurídico, que o Estado (direito oficial) nega, reconhece ou tolera, constitui-se no problema e no objetivo da pesquisa. Conclui-se que o fenômeno Reclame Aqui se enquadra na referida perspectiva teórico-antropológica. Isso em razão do fato de se constituir em meio de solução de conflitos relativos aos direitos do consumidor sem, no entanto, apenas se pautar nas normas do direito oficial, mas, adotando soluções criativas, não dogmáticas, que visam sobretudo a solução do problema, dando, assim, provas de visão alargada do Direito, cujas principais referências são a eficácia e a ética.

PALAVRAS-CHAVE: Antropologia Jurídica; Direitos do Consumidor; Ética; Pluralismo Jurídico; Sociedade da Informação.

\section{THE PHENOMENON "PLACE YOUR COMPLAINTS” FROM THE POINT OF VIEW OF JURIDICAL ANTHROPOLOGY: AN EXAMPLE OF JURIDICAL PLURALISM}

ABSTRACT: The phenomenon 'Place your complaints', a digital channel by which suppliers and consumers dialogue on stalemates and solve their conflicts (consumers'

\footnotetext{
"Mestrando em no Programa em Direito da Sociedade da Informação do Centro Universitário das Faculdades Metropolitanas Unidas (FMU-SP); Advogado, Brasil. E-mail: m-tadeu-nascimento@uol.com.br

${ }^{* *}$ Doutor em Direito pela Universidade de São Paulo (USP); Docente, pesquisador e orientador do Curso de Graduação em Direito e do Mestrado em Direito da Sociedade da Informação do Centro Universitário das Faculdades Metropolitanas Unidas (FMU-SP), Brasil.
} 
rights), is discussed. Methodology comprises a review of the literature and a direct analysis on the functionality of the site. The issues and the aims of current paper are to verify whether the digital channel may be inserted within the perspective of mixed systems of Law, following contemporary Juridical Anthropology. The latter insists that within a determined social field there is a possibility to identify behaviors linked to more than one juridical system which the State denies, acknowledges or tolerates. Results show that 'Place your complaints' may be inserted within the theoretical and anthropological perspective due to the fact that it become a way for the solution of conflicts related to consumers' rights. Without being exclusively based on official legal norms, it adopts creative, non-dogmatic solutions that work out a solution for the problem. The legal vision, based on efficiency and ethics, is consequently amplified.

KEY WORDS: Information society; Juridical anthropology; Juridical pluralism; Consumer rights; Ethics.

\section{EL FENÓMENO “RECLAME AQUII" BAJO LA ANTROLOPOLOGÍA JURÍDICA: UN EJEMPLO DE PLURALISMO JURÍDICO}

RESUMEN: Se aborda el fenómeno Reclame Aquí, sitio digital por medio del cual suministradores y consumidores dialogan sobre impases y resuelven sus conflictos (derechos de los consumidores). El método es la revisión bibliográfica y el análisis directo de la funcionalidad del referido sitio. Verificar la posibilidad de cuadrar ese medio digital en la perspectiva de los sistemas mixtos de Derecho, en conformidad con la definición de la Antropología Jurídica contemporánea, la cual sostiene que en un campo social determinado es posible identificar comportamientos relacionados a más de un sistema jurídico, que el Estado (derecho oficial) niega, reconoce o tolera, se constituye en el problema y en el objetivo de esa pesquisa. Se concluye que el fenómeno Reclame Aquí se cuadra en la referida perspectiva teórico-antropológica. Eso ocurre por el hecho del sitio constituirse en un medio de solución de conflictos relativos a los derechos del consumidor que, sin embargo, no se ampara solo en las normas del derecho oficial, pero adopta soluciones creativas, no dogmáticas, que buscan, sobretodo, la solución del problema, dando, así, pruebas de una visión extendida del derecho, cuyas principales referencias son la eficacia y la ética.

PALABRAS-CLAVE: Sociedad de Información; Antropología del derecho; Pluralismo Jurídico; Derechos del Consumidor; Ética. 


\section{INTRODUÇÃO}

O tema objeto da pesquisa refere-se à ocorrência nas sociedades contemporâneas do fenômeno do pluralismo jurídico, conforme teorizado pela mais moderna corrente da antropologia jurídica, denominada de pluralismo jurídico ou sistemas mistos de Direito, incidindo a análise especificamente sobre as relações de consumo na sociedade brasileira e sobre o canal virtual de intermediação dessa mesma relação denominado "Reclame Aqui", na perspectiva de que esse site exemplifica a ocorrência do pluralismo jurídico.

A tendência contemporânea da antropologia jurídica - conhecida por pluralismo jurídico ou sistemas mistos de Direito - insiste em que toda sociedade possui uma multiplicidade hierarquizada de ordenamentos jurídicos que o direito oficial reconhece, tolera ou nega. Assim, há pluralismo jurídico quando é possível identificar em dado campo social comportamentos relativos a mais de um único sistema de direito. Quanto ao método, a corrente doutrinária recomenda a busca das manifestações do direito em campo ampliado para além dos limites fixados pelo Estado e seus órgãos. Politicamente, recomenda também que seja relativizada a tendência de o Estado apresentar-se por meio da supremacia da lei na hierarquia das fontes do Direito, como sendo a principal ou exclusiva. Nesses termos, o pluralismo jurídico é encarado como fenômeno universal, sob a perspectiva de que todas as sociedades praticam a um só tempo vários sistemas de direito, sendo que algumas o valorizam mais do que outras, e que nas chamadas sociedades modernas o Estado advoga ideologicamente o seu monopólio do Direito, como condição do bem geral. Assim, a delimitação do tema neste estudo concerne à busca de verificação pela análise do site "Reclame Aqui", a saber, se o mesmo se constitui em um exemplo de ocorrência real, prática, dos postulados teóricos acima mencionados, com o objetivo de contribuir ao debate do pluralismo jurídico na sociedade brasileira contemporânea por meio da análise de situação específica atinente às relações de consumo e a fim de ampliar a perspectiva de compreensão do fenômeno jurídico e, portanto, do Direito em sentido ampliado, para além da normatividade oficial.

Como hipótese, sustenta-se que a grande aceitação e uso do canal de comunicação, exposição e solução de conflito em que se constitui o fenômeno "Reclame Aqui" advém justamente da grande vitrine em que se transformou expondo o comportamento dos fornecedores e que em grande medida adota mecanismos de solução de conflitos filiados sobretudo aos sistemas tradicionais de direito, como 
os das sociedades ameríndias, que antes do recurso à repressão ou de outros meios violentos e homogêneos de sanções recorrem a modalidades de medidas informais como as inibidoras e apenas quando esgotadas estas é que se faz recurso às punitivas. As medidas inibidoras correspondem a procedimentos informais e tomam as cores do ridículo e da exposição pública daquele que está praticando ação antissocial, reprovável, o que pode exatamente, em razão da exposição pública, levá-lo a se enquadrar ao respeito do que é socialmente valorizado.

$\mathrm{O}$ método aqui empregado é o da análise da literatura da antropologia jurídica e a verificação de sua pertinência para análise e enquadramento do fenômeno "Reclame Aqui" enquanto exemplo prático das afirmações teóricas, bem como análise da produção jurídica contemporânea relativa aos direitos do consumidor e das ciências sociais lato senso relativa à sociedade da informação. Ademais, a análise do próprio sítio da Internet - Reclame Aqui -, de suas principais características e do fluxo de seu funcionamento enquanto meio de informação e espaço de exposição pública, reclamação e de solução de conflito. O conjunto dessas atividades analíticas empregadas é que permitiu a verificação da hipótese antes formulada.

O estudo se justifica do ponto de vista social na medida em que o fenômeno "Reclame Aqui" vem desempenhando papel significativo para a melhoria das relações de consumo e para a resolução de conflitos no campo das mesmas relações, a partir do emprego de meios até bem pouco tempo não usuais, os quais não estão atrelados ao Estado. Do ponto de vista acadêmico, se justifica igualmente na medida em que adensa a produção do conhecimento sobre atividades práticas, concretas, exemplares, que podem confirmar os postulados teóricos da antropologia jurídica contemporânea, tão pouco conhecida no meio jurídico. Do ponto de vista pessoal, o estudo também se justifica, tanto porque um dos autores tem se dedicado ao longo do tempo ao estudo e à advocacia relativa aos direitos dos povos indígenas, desenvolvidos com base na mesma teoria antropológica aqui enfocada, quanto porque o outro coautor é advogado militante no direito da sociedade da informação, em cujo ambiente situa-se e se desenvolve o site "Reclame Aqui", objeto da análise, que como se verá ao longo do desenvolvimento do presente estudo, também se adequa ao enfoque teórico da corrente antropológica denominada de pluralismo jurídico ou sistemas mistos de direito.

Apresentadas essas considerações sobre o tema, delimitação, objetivo, hipótese, metodologia e justificativas, cabe situar o campo de incidência do estudo e o ambiente no qual ocorre o fenômeno "Reclame Aqui", que é a rede mundial de 
computadores que consolidou seu funcionamento no Brasil a partir de 1995 e a subsequente organização do desenvolvimento do presente estudo. Assim, no item 2 abordam-se as consequências da introdução da Internet no Brasil sobre as relações de consumo e seus reflexos na apreensão e aplicação do Direito. Em seguida, no item 3, estuda-se o fenômeno "Reclame Aqui" à luz da contemporânea antropologia jurídica e os direitos consumeristas. Em seguida, no item 4 adentra-se no estudo da concepção antropológica de pluralismo jurídico, propriamente dita. No item 5, antes das considerações finais, busca-se estudar e compreender o Direito na atual sociedade da informação a partir de todas as considerações anteriores.

\section{INTERNET E AS ALTERAÇÕES NAS RELAÇÕES DE CONSUMO: DO DIREITO ESTATAL AO DIREITO COMUNITÁRIO}

Nos anos seguintes à instalação da Internet no Brasil houve rápida expansão ao seu acesso, acompanhando movimento mundial. Essa popularização irradiou para diversas áreas da vivência humana muitas práticas inerentes ao universo digital. O comércio passou a ser também eletrônico e os comportamentos dos consumidores mudaram em razão do crescimento de redes sociais e de todo tipo de softwares que passaram a fazer parte do cotidiano de enormes quantidades de pessoas. A proteção do consumidor, iniciada legalmente em 1990, começou a sofrer grandes alterações com a transferência de muitas práticas cotidianas para o mundo digital. Nessa nova contextualização, as relações de consumo sofreram mudanças e o Serviço de Atendimento ao Consumidor (SAC), antes ineficiente ou precário em razão do caráter "secreto" e "individual" das reclamações, destituindo o consumidor de qualquer parcela real de poder na proteção de seus direitos, passou a contar com nova forma ou ferramenta de comunicação que propiciou efetiva reinvindicação dos direitos, por meio da "ameaça" de possível propagação exponencial das eventuais práticas dos fornecedores de bens, serviços e produtos.

Decertaforma, as novas tecnologias, nocampodos direitos dos consumidores, fizeram migrar parcela do poder, antes preponderantemente nas mãos do mercado ( $2^{\circ}$ setor), sem qualquer possibilidade de equacionamento empírico adequado pelo Estado ( $1^{\mathrm{o}}$ setor) ao indivíduo inserido na sociedade do consumo de massa, nascendo os sítios digitais voltados às reclamações dos consumidores, destacando- 
se entre eles o Reclame Aqui (Widea Soluções Digitais Ltda.). A referida empresa se apresenta como um meio de convergência entre a empresa e o consumidor na sociedade da informação. Em estudo a seu respeito na área da comunicação, Narjara Bábara Xavier da Silva e Cláudio Cardoso Paiva aduzem que:

De acordo com o Diretor do site Maurício Vargas em 90\% dos casos as pessoas que cadastram suas reclamações no banco de dados do site são clientes que já tentaram inicialmente solucionar seus problemas diretamente com as empresas reclamadas, mas que não foram atendidos satisfatoriamente. Por esse motivo, este meio de comunicação é entendido pela Widea como uma esfera intermediária entre a empresa reclamada e o outro órgão oficial em defesa do consumidor. $\mathrm{Na}$ verdade, o Reclame Aqui já pode ser considerado um site que conquistou o espaço dos órgãos de defesa do consumidor. Isso porque o retorno obtido por esse novo meio é bem mais satisfatório para os consumidores do que pelo meio tradicional. Enquanto o Procon estabelece a data limite para o retorno por parte das empresas entre 100 dias, muitas vezes não alcançando a resolução do caso, o site Reclame Aqui possui em média três dias para a resposta e que, por motivos da pressão posta pelos consumidores através de discussões e disseminação de opiniões sobre determinada empresa, muitas vezes os casos são resolvidos.

A política de comunicação do site Reclame Aqui, bem como a manutenção de um bom relacionamento com os seus públicos - consumidores diretos e varejistas com experiência em canais de internet e com histórico de compras feitas via web, são direcionadas com base em três documentos que regem a análise, postagem, acompanhamento e avaliação das reclamações, são eles: Termos de Uso; Políticas de Privacidade; e Direitos do Consumidor ${ }^{01}$.

Ao se falar em sociedade é preciso entendê-la como um acervo de emanações culturais ou conexões institucionais, sem se descurar do trajeto histórico, os quais conduzem à formação e organização necessárias para a sobrevivência e convivência humanas. Deste modo, é possível adjetivar dada sociedade, dependendo do momento preponderante. Assim, é possível se falar em sociedade moderna, sociedade capitalista, sociedade industrial etc. As sociedades contemporâneas, com ênfase nas dotadas de tecnologia, são chamadas de sociedade da informação ou sociedade do conhecimento ${ }^{02}$.

Os processos sociais de interação e relacionamento, na dita sociedade

\footnotetext{
${ }^{01}$ SILVA, Narjara Bárbara Xavier; PAIVA, Cláudio Cardoso. Comunicação Digital - Estudo do Site Reclame Aqui - Um novo meio convergente entre a empresa e o consumidor 2.0. Revista Eletrônica Temática, ano V, n. 12, dez. 2009, p. 3-4.

${ }^{02}$ IAMUNDO, Eduardo. Sociologia e Antropologia do Direito. São Paulo: Saraiva, 2013, p. 131.
} 
contemporânea, são em boa parte mediados principalmente pelas mídias comunicacionais, as quais se mostram como importante espaço público ou "ágora"03 em que os atores ou agentes sociais alcançam legitimação, voz e visibilidade. Segundo Marília de Oliveira Cruz:

O desenvolvimento e a utilização, cada vez maior, dos dispositivos comunicacionais tecnológicos como meios de interação intensificam o processo de midiatização da sociedade ao possibilitarem o surgimento da comunicação em rede. Esse modelo comunicacional trouxe mais agilidade ao ato comunicativo, uma vez que, permitiu minimizar as barreiras espaço-temporais, facilitando a interlocução entre os sujeitos e aumentando o poder de circulação das informações. Como consequência, houve a inserção de múltiplas "vozes" nas relações comunicacionais, o que vem posicionando as mídias digitais como um importante espaço de produção e divulgação da informação, mas também, como uma das principais arenas de embates discursivos onde a visibilidade e a legitimação das "falas" são disputadas por diferentes atores sociais ${ }^{04}$.

\section{Para Manuel Castells vive-se em uma sociedade em rede, localizada na "Galáxia da Internet", neste sentido:}

A Internet é um meio de comunicação que permite, pela primeira vez, a comunicação de muitos com muitos, num momento escolhido, em escala global. Assim como a difusão da máquina impressora no Ocidente criou o que MacLuhan chamou de a "Galáxia de Gutenberg", ingressamos agora num novo mundo de comunicação: a Galáxia da Internet $[\ldots]^{05}$.

\section{Assenta ainda o mesmo autor:}

A influência das redes baseadas na Internet vai além do número de seus usuários: diz respeito também à qualidade do uso. Atividades

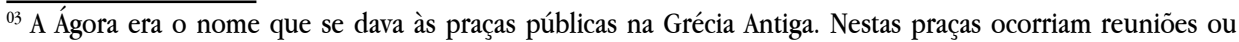
assembleias onde os gregos, principalmente os atenienses, discutiam assuntos ligados à vida da cidade (pólis). As assembleias aconteciam na Ágora e os gregos podiam decidir sobre temas ligados à justiça, obras públicas, leis, cultura etc. Os cidadãos votavam e decidiam através do voto direto. Também era um espaço público de debates para os cidadãos gregos. Disponível em: < http://www.superpesquisa.com>. Acesso em: 18 dez. 2015.

${ }^{04}$ CRUZ, Marilia de Oliveira. Midiatização e relações de consumo: um estudo de caso sobre as interações dos discursos entre consumidores e empresas no site Reclame Aqui. 2013. Dissertação (Mestrado em Comunicação) - Pontifícia Universidade Católica de Minas Gerais, Belo Horizonte, p. 11.

${ }^{05}$ CASTELLS, Manuel. A galáxia da internet: reflexões sobre a internet, os negócios e a sociedade. Tradução Maria Luiza X. de A. Borges. Rio de Janeiro: ZAHAR, 2003, p. 8.
} 
econômicas, sociais, políticas, e culturais essenciais por todo o planeta estão sendo estruturadas pela Internet e em torno dela, como por outras redes de computadores $[\ldots]^{06}$.

Por outro turno, o pluralismo jurídico ou sistema misto de direito "[...] pressupõe a existência de mais de um direito ou ordem normativa no mesmo espaço geográfico" ${ }^{\circ 7}$. De acordo com Boaventura de Sousa Santos, o sistema misto ganha corpo ou lugar sempre que contradições se condensam na criação de espaços sociais no seio da sociedade e originam litígios ou embates, os quais são processados ou conduzidos sob o fundamento de recursos normativos e institucionais internos ${ }^{08}$.

A ideia central desse pensamento, embora tenha recuado no início do século XX, tendo em vista as teses do positivismo jurídico, já na segunda metade do referido século retornou com todo o vigor para constituir um dos principais temas da antropologia do direito ${ }^{09}$.

Caracteristicamente o direito estatal, com o positivismo, é um fenômeno burocratizado, instrumento de poder e ciência jurídica visto como tecnologia. Seus operadores (advogados, juízes, promotores, delegados etc.) voltam seus olhares à tecnicidade e se alienam no processo de construção do direito enquanto instrumento de gestão social. Assim, o direito não é visto ou compreendido em sua função social ou como um "conhecimento" ou "saber" que também serve à luta ou tensão social emanada e frequente no mundo vivenciado. Ademais, o direito não é entendido como meio de mudança ou prática virtuosa em prol do homem. Isso produz na sociedade uma tendência na busca por meios alternativos de resolver suas pendências, fazendo emergir no seio social, especialmente com as novas tecnologias, um direito do tipo comunitário (à semelhança dos povos tradicionais), o qual leva em conta a legitimidade dos atores envolvidos. Conforme alerta Tércio Sampaio Ferraz Junior:

[...] As sociedades estão em transformação e a complexidade do mundo está exigindo novas formas de manifestações do fenômeno jurídico. É possível que, não tão distantemente no futuro, essa forma compacta do direito instrumentalizado, uniformizado e generalizado sob a forma estatal de organização venha a implodir, recuperando-se,

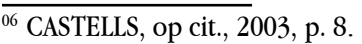

${ }^{07}$ ASSIS, Olney Queiroz; KUMPEL, Vitor Frederico. Manual de antropologia jurídica. São Paulo: Saraiva, 2015, p. 50 .

${ }^{08}$ SANTOS, Boaventura de Souza. O discurso e o poder: ensaio sobre a sociologia da retórica jurídica. Porto Alegre: Fabris, 1988, p. 76.

${ }^{09}$ Ibidem, p. 50.
} 
em manifestações espontâneas e localizadas, um direito de muitas faces, peculiar aos grupos e às pessoas que os compõem. [...] Por isso tudo, a consciência da nossa circunstância não deve ser entendida como um momento final, mas como um ponto de partida. Afinal, a ciência não nos libera porque nos torna mais sábios, mas é porque nos tornamos mais sábios que a ciência nos libera [...] pensar o direito, refletir sobre suas formas hodiernas de atuação, encontrar-lhe um sentido, para então vivê-lo com prudência, esta marca virtuosa do jurista $[\ldots]^{10}$.

A utilidade da antropologia jurídica salta aos olhos quando viabiliza a descoberta e o entendimento do direito sob o véu dos códigos, bem como fomenta a sociedade para a recepção da dinâmica jurídica que está em curso e direciona para um direito mais maleável, voltado às mediações, transações ou punições flexíveis, conduzindo as pessoas ao conhecimento de que há muito tempo e em algumas sociedades o gênero humano, que, equivocadamente, chama-se de "primitivo", já praticava estes procedimentos ou ainda os empregam.

Entre o direito do tipo estatal e do tipo comunitário, este último ganha espaço na sociedade da informação ou do conhecimento, podendo se observar no sítio "Reclame Aqui" um espaço digital midiático, em rede, em que os consumidores insatisfeitos com produtos, serviços e atendimentos prestados pelas empresas dos mais diferentes seguimentos, divulgam suas reclamações. Nascido há quinze anos, o sítio digital recebe por dia milhares de reclamações, indicando sua página de abertura o atendimento de quinze milhões de reclamações $/$ mês $^{11}$, as quais são alocadas na página principal até que a fornecedora de serviços ou produtos contate o consumidor para solucionar o problema. Sobrevindo o contato o consumidor possui a prerrogativa de avaliar publicamente o atendimento, dando seu voto acerca da 'satisfação' e da possibilidade de futuros negócios (para recontratar ou adquirir os serviços ou produtos novamente). Referidas informações alimentam um ranking de medição de desempenho dos fornecedores que é disponibilizado na própria página. Ante essa constatação e a visibilidade gerada pelo sítio virtual, instala-se discussão de contornos jurídicos do tipo "não estatal", com o empoderamento dos consumidores na proteção de seus direitos em razão da "ameaça" de dano à imagem das empresas faltosas, representada pelo volume de reclamações apresentadas contra elas. Cuidase de uma força frente ao jogo do mercado. Em suma, não é exagerado dizer que o

\footnotetext{
${ }^{10}$ FERRAZ JR, Tércio Sampaio. Introdução ao estudo do direito: técnica, decisão, dominação. $8^{\mathrm{a}}$ ed. São Paulo: Atlas, 2015, p. 7-9.

${ }^{11}$ Disponível em: < http://www.reclameaqui.com.br/> Acesso em: $18 \mathrm{dez} .2015$.
} 
trabalho prestado pelo canal digital se trata de um fenômeno social e jurídico a um só tempo.

Tendo em conta todas essas perspectivas, analisar-se-á adiante o fenômeno social "Reclame Aqui" sob a luz da antropologia jurídica contemporânea, que revela tratar-se de um exemplo dentro da sociedade contemporânea de prática jurídica que se situa aquém ou mesmo além do tipo estatal.

\section{O FENÔMENO "RECLAME AQUI" À LUZ DA CONTEMPORÂNEA ANTROPOLOGIA JURÍDICA E OS DIREITOS CONSUMERISTAS}

$\mathrm{Na}$ legislação, bem como na doutrina, o direito do consumidor é relativamente recente, tendo o seu aparecimento, admitido como um ramo do Direito $^{12}$, ocorrido essencialmente na segunda metade do século XX. Existem contornos permanentes do referido seguimento do direito de forma dispersa em inúmeras jurisprudências, em diversificadas normas e inseridos nos costumes e na cultura dos mais variados países. Entretanto, tal segmento não figurava como uma espécie jurídica diferenciada e não admitia a nomenclatura apresentada nos dias de hoje. Ressaltando-se na doutrina nacional pertinente à questão o posicionamento de Cláudia Lima Marques, ao elucidar que:

A ideia central é possibilitar uma aproximação e uma relação contratual mais sincera e menos danosa entre consumidor e fornecedor. Transparência significa informação clara e correta sobre o produto a ser vendido, sobre o contrato a ser firmado, significa lealdade e respeito nas relações entre fornecedor e consumidor $[\ldots]^{13}$.

O Código de Defesa do Consumidor (CDC), portanto, foi pautado na regulamentação das relações de consumo, na garantia dos direitos dos consumidores e, ainda, na qualidade dos produtos e serviços oferecidos, além do atendimento ao cliente. Tal diploma legal objetiva diminuir a diferença de poder existente entre o consumidor e o fornecedor (mercado versus consumidor, lucro versus satisfação), definindo ambas figuras, além das práticas comerciais abusivas e tipos de penalidades

\footnotetext{
${ }^{12}$ Ramo das ciências sociais.

${ }^{13}$ MARQUES, Cláudia Lima. Contratos no Código de Defesa do Consumidor: o novo regime das relações contratuais. $5^{\text {a }}$ ed. São Paulo: Revista dos Tribunais, 2006, p. 206. V. Ainda sobre o tema, de mesma coautoria: BENJAMIN, Antônio Herman V.; MARQUES, Cláudia Lima; BESSA, Leonardo. Manual de Direito do Consumidor. $4^{\mathrm{a}}$ ed. rev. atual. e ampl. São Paulo: Revista dos Tribunais, 2013.
} 
a serem impostas. Regula, assim, os possíveis conflitos entre esses dois polos da relação de consumo.

O CDC é conhecido como um microssistema aplicável às relações de consumo, de natureza predominantemente principiológica, que ocasionou importantes inovações para o universo jurídico brasileiro, especialmente (i) a positivação de conceitos importantes como o de consumidor e o de fornecedor, (ii) o reconhecimento da situação de vulnerabilidade do consumidor, (iii) a instituição de regras específicas como a responsabilidade objetiva do fornecedor e de técnicas de facilitação da defesa do consumidor em juízo e, ainda, (iv) a criação de um rol de direitos básicos dos consumidores.

A atual conjectura jurídica relativa aos direitos dos consumidores no Brasil revela que o legislador calcado na premissa de reconhecimento da vulnerabilidade no mercado de consumo buscou, ao estabelecer critérios objetivos e subjetivos de elevação da participação do consumidor frente ao fornecedor, validar a importância da defesa do reconhecidamente vulnerável nas relações de consumo.

No mesmo passo em que se reconhece a importância da efetivação do comando constitucional (art. $5^{\circ}$, XXXII, CF) deve-se, também, ter em mente as transformações sociais havidas pós-período constitucional, e na chamada sociedade contemporânea complexa e em mutação constante (devido entre outras causas às novas tecnologias), tornando o aparato estatal na proteção de certos direitos (como, por exemplo, do consumidor em massa), em certos aspectos, empiricamente ineficientes, em razão da burocracia e dos custos, impondo, assim, a busca de meios alternativos. Sem dúvida alguma, ao mesmo tempo em que as novas tecnologias tornaram determinante o jogo de poder do mercado, possibilitaram igualmente a convergência de vozes e manifestações dos consumidores por meio da rede mundial de computadores (Internet).

A Internet (instrumento), e respectivamente as redes sociais (forma), foram os principais instrumentos facilitadores desse movimento rumo à convergência e proteção dos direitos dos consumidores. A Internet, ou rede mundial, teve seu surgimento em idos de 1960 no exército dos Estados Unidos da América com a proposta clara de criar um modo de transmitir dados entre dois aparelhos de computador. Já no final dos anos 60, a Agência de Projetos Avançados (ARPA), do Departamento de Defesa dos EUA, transferiu para a Rand Corporation a tarefa de desenvolver um sistema de telecomunicações que protegesse a comunicação dos 
comandantes do país, no caso de ataque nuclear. Este projeto ganhou o nome de Projeto Arpanet ${ }^{14}$. Com relação ao Projeto Arpanet, é importante salientar que pequenas redes locais (LAN) foram criadas e posicionadas em lugares estratégicos do país, e ligadas por meio de redes de telecomunicação geográfica (WAN). Assim, se algum ponto estratégico fosse destruído, as "redes conexas" compostas por redes locais distantes umas das outras, todavia ligadas entre si, protegeriam a comunicação (por meio das redes coligadas). Este modelo sistemático (de redes interligadas), foi nominado de Internet (Inter Networking) ${ }^{15}$. Embora em 1973 a Internet tenha ganhado corpo (aumentado), quando o Departamento de Pesquisa Avançada da Universidade da Califórnia e responsável pelo Projeto Arpanet registrou o Protocolo de Controle da Transmissão (protocolo TCP/IP - Internet Protocol ou Protocolo Internet ${ }^{16}$ foi somente a partir do final da década de 80 e começo da década de 90 que o acesso aos microcomputadores, em razão da redução de custos na sua produção, foi possível ultrapassar a marca de um milhão de usuários. Também, nesta década houve o direcionamento da Internet para fins comerciais. A Internet tornouse uma realidade para boa parte da humanidade e seus efeitos podem ser observados na alteração do cotidiano de grande número de pessoas. Sem adentrar na febre dos smartphones, responsáveis pela inserção digital de milhares de pessoas, estima-se 93 milhões de usuários ${ }^{17}$.

Firmadas essas premissas, surge então, no ano 2000, a plataforma não oficial ou não governamental de integração entre consumidores e fornecedores, denominada "Reclame Aqui", salientando seu fundador, Maurício Vargas, que "[...] naquela oportunidade, perdi um negócio em São Paulo devido a um 'overbooking'. Foi então que resolvi criar um site para mostrar a indignação de quem é lesado pelos serviços que as empresas oferecem [...]"18.

A experiência propulsora está relacionada também à ineficácia dos meios ordinários de solução de problemas disponibilizados pelos fornecedores, seu

${ }^{14}$ PAESANI, Liliana Minardi. Direito e Internet: liberdade de informação, privacidade e responsabilidade civil. 6. ed. São Paulo: Atlas, 2013, p. 10.

${ }^{15}$ Idem.

${ }^{16}$ PAESANI, Liliana Minardi. Direito e Internet: liberdade de informação, privacidade e responsabilidade civil. $6^{\mathrm{a}}$ ed. São Paulo: Atlas, 2013, p. 10.

${ }^{17}$ GOMES, Helton Simões: "Os números mostram que a população conectada cresceu, enquanto a de indivíduos 'móveis' avançou em ritmo mais acelerado. Se em 2010, os internautas eram 82 milhões, em 2015, passaram a 117 milhões. Já o número de donos de smartphone pulou de 10 milhões para 93 milhões no mesmo período". (Disponível em: < http://g1.globo.com/tecnologia/noticia/2015/08/conexao-internet-smartphone-dobrano-brasil-em-2015-diz-google.html > . Acesso em: 14 dez. 2015).

${ }^{18}$ BOSCO, Tiago. Os bastidores do Reclame Aqui e o novo perfil do consumidor. 2013. Disponível em: < http:// www.revistawide.com.br/e-commerce/bastidores-do-reclameaqui > . Acesso em: 14 dez. 2015. 
idealizador " $[. .$.$] notou a necessidade da criação de um canal em que o consumidor$ pudesse expor os problemas e a ineficiência dos canais de atendimento das empresas e assim surgiu o 'Reclame Aqui'”19.

O cadastramento do usuário é feito mediante a informação dos dados pessoais e não é permitida a postagem em modo anônimo. Outra particularidade da ferramenta é que o usuário não pode retirar a reclamação após registrá-la, pois segundo seu termo de uso a mesma ficará como conteúdo estatístico do site e como referência para outros consumidores. Vários são também os alertas com relação ao conteúdo das reclamações, que não podem ser feitos com vocabulário e forma irrestrita, devendo obedecer às regras constantes no termo de uso.

Existe, também, uma espécie de certificação digital, denominado Selo RA1000, para as empresas que atendam aos seguintes critérios: (a) possuir um número de avaliações igual ou superior a 50; (b) possuir Índice de Resposta igual ou superior a 90\%; (c) possuir Índice de Solução igual ou superior a 90\%; (d) possuir Média das Avaliações (dadas pelo consumidor) igual ou superior a 7; e (e) possuir Índice de Novos Negócios (Voltaria a fazer negócios?) igual ou superior a $70 \%{ }^{20}$.

$\mathrm{O}$ alastramento do consumidor na web é sentido também em outros sítios e ferramentas, gerando nas empresas o fenômeno do monitoramento de sites e principalmente de redes sociais, não caracterizando qualquer novidade no mercado atual, sendo certo que diversas são as empresas que se cuidam a prestar o serviço de monitoramento de ferramentas e redes sociais, inclusive com o surgimento do denominado profissional de social media ${ }^{21}$.

É possível perceber que as mudanças em curso estão dotando os consumidores de uma força ou capacidade expressiva que se no nível individual se caracteriza como um micropoder no sentido coletivo se firma como uma revolução, ou um contra fluxo nas relações com as organizações e instituições desprovidas de sensibilidade para entender o consumidor contemporâneo, que na atualidade conta com a mobilidade das novas tecnologias e tem espaço na 'ágora virtual'22.

\footnotetext{
${ }_{19}$ Disponível em: < http://www.reclameaqui.com.br/como_funciona/o-que-e-o-reclame-aqui_7/>. Acesso em: 14 dez. 2015.

${ }^{20}$ Disponível em: < http://www.reclameaqui.com.br/selo/> . Acesso em: 14 dez. 2015.

${ }^{21}$ TEMPERINI, Alessandre. "Um social media manager é aquela pessoa que vai criar conteúdo, responder aos comentários e questionamentos e lidar com toda aquela audiência que interage com a página que a marca ou a empresa possui em uma rede social". (Disponível em: <http://papouniversitario.anhembi.br/2015/04/trabalhar-com-facebook-entenda-o-que-e-e-o-que-faz-o-profissional-de-social-media/> . Acesso em: 11 jan. 2016).

${ }^{22}$ GALINDO, Daniel; BASSETTO, Jefferson. As muitas vozes do consumidor contemporâneo ecoam na ágora virtual. In: CONGRESSO BRASILEIRO DE CIÊNCIA DA COMUNICAÇÃO, 34, Recife. Anais eletrônicos... Disponível em: <http://danielgalindo.ppg.br/As\%20muitas\%20vozes\%20do\%20consumidor\%20contemporaneo\%20 ecoam\%20na\%20agora\%20virtual.pdf>. Acesso em: 11 nov. 2015.
} 
Um fato a ser observado, e talvez não previsto sequer por seu fundador, considerando as intenções que o fizeram idealizar a ferramenta, é de que passou o "Reclame Aqui" a servir não mais como um simples depósito de reclamações e sim como uma espécie de vitrine para outros consumidores, que pretendem saber qual é a reputação da empresa por ele buscada, na medida em que ao analisar os acessos, constatou-se que $95 \%$ das pessoas que acessam todos os dias o site não entram para reclamar, e sim para ver a reputação da empresa antes de comprar algum produto ou adquirir algum serviço. E não é só isso. Até o Poder Público Oficial (o Estado), socorre-se das informações nele contidas. Informa Marilia Oliveira Cruz em sua dissertação que no ano de 2011 o Ministério Público do Rio de Janeiro moveu Ação Civil Pública em face da loja virtual 'Americanas.com' porque a empresa descumpriu seus deveres de entrega do produto aos consumidores. Nas decisões, seja na primeira instância, seja na segunda, um dos argumentos base para a proibição de o sítio realizar qualquer tipo de comercialização foram as reclamações registradas no site "Reclame Aqui". Outro exemplo sucedeu com as operadoras de celulares no ano de 2012, as quais foram suspensas pela Agência Reguladora de Telecomunicações (ANATEL) até que cumprissem as metas estabelecidas pelo órgão.

Visando atrair e manter a fidelidade desse público a ferramenta disponibiliza rankings, classificando diversos nichos, dentre eles as empresas 'mais reclamadas do dia', 'mais reclamadas da semana', 'mais reclamadas nos últimos 30 dias', 'empresas recém-cadastradas com mais reclamações', 'melhores índices de solução', 'melhores índices de voltar a fazer negócios', 'melhores notas médias', 'mais reclamadas nos últimos 12 meses'.

O êxito da ferramenta resulta do registro de que, atualmente, 15.000.000 (quinze milhões) de pessoas por mês acessam o seu arquivo de reclamações. Segundo recente pesquisa do Pew Research Center, divulgada em 18 de março de 2015, que teve como público alvo os adultos, identificou-se que no Brasil $75 \%$ (setenta e cinco por cento) dos entrevistados afirmaram que acessam a Internet diariamente, ficando o país na $7^{\mathrm{a}}$ posição, e acima da média global da amostra, que foi de $66 \%$ (sessenta e seis por cento ${ }^{23}$. O uso da Internet, e por consequência, de ferramentas digitais por consumidores, reafirma a busca por meios alternativos de solução de conflito, e também a mudança da perspectiva tradicional dos meios de atendimento a demandas advindas de relações de consumo. Antes, talvez, o consumidor sempre

\footnotetext{
23 Disponível em: <http://www.pewglobal.org/2015/03/19/internet-seen-as-positive-influence-on-education -but-negative-influence-on-morality-in-emerging-and-developing-nations/technology-report-11/> . Acesso em: 15 dez. 2015.
} 
estivesse distante da empresa, especialmente nos momentos de reclamação, ou seja, o contato era basicamente por telefone ou até carta, a depender da situação.

Quebrando todos estes paradigmas, a Internet e ferramentas como o "Reclame Aqui" fazem perceber que, embora separados por um universo de dados, informações e códigos-fonte (web), os consumidores estão cada vez mais próximos das empresas (em poder), haja vista que, querendo ou não, parte do público da maioria das companhias existentes atualmente também está na Internet, não pretendendo o fornecedor de produtos, bens e serviços ver o seu nome ou a sua reputação manchada em qualquer espaço, principalmente na rede mundial de computadores, onde qualquer informação é facilmente compartilhada, replicada, e tem o poder de atingir um número indefinido de pessoas, e quiçá possíveis futuros consumidores daquela marca.

A seguir dedica-se espaço para o estudo da concepção antropológica do pluralismo jurídico a qual, como se verá, parece abarcar de forma bastante adequada o fenômeno "Reclame Aqui", que se acaba de estudar.

\section{CONCEPÇÃO ANTROPOLÓGICA DE PLURALISMO JURÍDICO}

A antropologia não é distinta das outras ciências humanas e sociais em razão do seu objeto de estudo. A história da disciplina determinou que começasse pelo estudo das sociedades tradicionais, ainda que outras ciências e o direito também tenham se preocupado com isso. Assim, no momento em que se voltou também para as sociedades complexas (modernas) percebe-se com maior vigor sua estreita ligação com o direito. A interdisciplinaridade de ambas justifica o interesse de uma pela outra ${ }^{24}$. De modo geral, os antropólogos entendem que o objetivo deste ramo da ciência é o conhecimento do homem por inteiro, em todas as sociedades e grupos humanos, destacando-se dela um aspecto triplo, a saber: (1) de ciência social, (2) de ciência humana, e (3) de ciência natural. Ciência social porque perscruta o homem enquanto indivíduo inserido na sociedade, comunidade e grupo organizado. Ciência humana porque busca conhecer o homem por meio de sua história, crença, arte, usos e costumes, magia, linguagem etc. Ciência natural porque visa conhecer o homem sob o aspecto 'progressivo' biologicamente considerado, genético, anatômico e fisiológico ${ }^{25}$. No pensamento de Lévi-Strauss:

\footnotetext{
${ }^{24}$ ASSIS, Olney Queiroz; KUMPEL, Vitor Frederico. Manual de antropologia jurídica. São Paulo: Saraiva, 2015, p. 13 .

${ }^{25}$ ASSIS, op cit., 2015, p. 13-14.
} 
[...] a antropologia não se diferencia das outras ciências humanas e sociais por um objeto de estudos que lhe seja próprio. A história quis que ela começasse por se interessar pelas sociedades ditas "selvagens" ou "primitivas" [...]. Mas esse interesse é de modo crescente, dividido com outras disciplinas, notadamente a demografia, a psicologia social, a ciência política e o direito. [...] ela procede de certa concepção do mundo ou de uma maneira original de colocar os problemas, uma e outra descobertas por ocasião do estudo dos fenômenos sociais [...] tornam manifestas certas propriedades da vida social, as quais a antropologia toma como seu objeto ${ }^{26}$.

O direito, ou o fenômeno jurídico, demanda abertura para o humano, para a história e o social deparando-se neste contexto com a antropologia, surgindo a partir daí a formatação da antropologia jurídica. E aqui calha a preciosa reflexão de Ferraz Jr:

O direito é um dos fenômenos mais notáveis na vida humana. Compreendê-lo é compreender uma parte de nós mesmos. É saber em parte por que obedecemos, por que mandamos, por que nos indignamos, por que aspiramos mudar em nome de ideais e por que em nome de ideais conservamos as coisas como estão. Ser livre é estar no direito e, no entanto, o direito também nos oprime e nos tira a liberdade. Por isso, compreender o direito não é um empreendimento que se reduz facilmente a conceituações lógicas e racionalmente sistematizadas. $\mathrm{O}$ encontro com o direito é diversificado, às vezes conflitivo e incoerente, às vezes linear e consequente. [...].

O direito é um mistério do princípio e do fim da sociabilidade humana. Suas raízes estão enterradas nesta força oculta que nos move a sentir remorso quando agimos indignamente e que se apodera de nós quando vemos alguém sofrer uma injustiça [...] estudo do direito é, pois, entronizar-se num mundo fantástico de piedade e impiedade, de sublimação e de perversão ${ }^{27}$.

\section{Complementando a reflexão, Assis e Kümpel contribuem com a seguinte} assertiva:

O direito serve para expressar e produzir a aceitação da situação existente, mas aparece também como sustentação moral da indignação e da rebelião. Assim, de um lado, o direito nos protege do poder arbitrário exercido à margem de toda regulamentação, dá oportunidades iguais e ampara os desfavorecidos. Por outro lado, é também um instrumento manipulável que frustra as aspirações dos menos privilegiados e permite o uso de técnicas de controle e dominaçãa ${ }^{28}$.

\footnotetext{
${ }^{26}$ LÉVI-STRAUSS, Claude. Anthropologie structurale. Paris: Plon, 1974, p. 378-379, tradução pessoal.

${ }^{27}$ FERRAZ JR, Tércio Sampaio. Introdução ao estudo do direito: técnica, decisão, dominação. 8. ed. São Paulo: Atlas, 2015, p. 1.

${ }^{28}$ ASSIS, Olney Queiroz; KÜMPEL, Vitor Frederico. Manual de antropologia jurídica. São Paulo: Saraiva, 2015, p. 47.
} 
Fincadas estas premissas, o pluralismo jurídico se caracteriza pelo reconhecimento da existência de mais de uma forma de "direito" ou "fenômeno jurídico" em um mesmo espaço social e geográfico. Ganha lugar em espaços sociais marcados por contradições, os quais geram disputas ou litígios a serem resolvidos com regulação interna. Neste sentido, Boaventura de Souza Santos traz à baila:

Essa tendência ou movimento é detectável por múltiplos sinais, mas os mais importantes são os que dizem respeito à criação, em certas áreas de controle social, de uma administração jurídica e judiciária paralela ou alternativa àquela que até agora dominou em exclusivo, recuperando ou reactivando, em novos moldes, estruturas administrativas de tipo popular ou participatório há muito abandonadas ou marginalizadas. Em áreas como a pequena delinquência e a pequena criminalidade, a ordem e a segurança públicas, a defesa do consumidor, a habitação, as relações entre vizinhos e as questões de família, criam-se tribunais sociais, comunitários ou de bairro presididos por juízes leigos, eleitos ou designados pelas organizações sociais, e em que a representação das partes por advogado não é necessária ou é até proibida. $O$ processamento das questões é informal e oral e, por vezes, nem sequer a sentença é reduzida a escrito ${ }^{29}$.

Assis e Kümpel invocam como exemplo o caso investigado nas favelas do Rio de Janeiro onde a associação de moradores passou a exercer a arbitragem de conflitos entre vizinhos, tornando-se um fórum jurídico ${ }^{30}$.

Neste arcabouço de ideias o "direito", sempre pensado no universo jurídico sob a perspectiva unilinear ${ }^{31}$, tem sua forma de análise modificada, anotando-se que as sociedades tradicionais (indígenas, comunidades quilombolas etc.), inseridas ou não na sociedade moderna, sempre apareceram tão civilizadas quanto ${ }^{32}$.

Destarte, é possível finalizar a interface entre a antropologia e o direito na seguinte observação:

A tendência atual da antropologia jurídica é a de substituir o dualismo normativo/processual por uma abordagem sintética. Os juristas e antropólogos, dessa corrente atual, estudam e propõem que se

${ }^{29}$ SANTOS, Boaventura de Souza. O discurso e o poder: ensaio sobre a sociologia da retórica jurídica. Porto Alegre: Fabris, 1988, p. 110-111.

${ }^{30}$ ASSIS, Olney Queiroz; KÜMPEL, Vitor Frederico. Manual de Antropologia Jurídica. São Paulo: Saraiva, 2015, p. 50.

${ }^{31}$ Unilinear está associado à primeira fase do evolucionismo social e que "inspira ainda em muito, em nossos dias, o ensino do Direito, 'considera as sociedades humanas como um conjunto coerente, unitário, submetido a leis de transformação globais e genéricas, que fazem passar todas as sociedades por fases idênticas no seu conteúdo e em sua sucessão, encaixando-se umas nas outras". BARBOSA, Marco Antonio. Direito Antropológico e Terras Indígenas no Brasil. São Paulo: Fapesp/Plêiade, 2001, p. 36.

32 BARBOSA, Marco Antonio. Direito Antropológico e Terras Indígenas no Brasil. São Paulo: Fapesp/Plêiade, 2001, p. 49. 
estudem as normas em seu conteúdo e a maneira como as concebem as partes quando sobrevém o conflito, dado que as normas não são estáticas, porque as partes podem negociá-las no curso do conflito ou mesmo depois da decisão. É importante, igualmente, que se estudem as razões da aplicação, do negligenciamento, da distorção e da violação delas.

Esta tendência mais moderna da antropologia jurídica, a do pluralismo jurídico, insiste em que "toda sociedade possui uma multiplicidade hierarquizada de ordenamento jurídicos que o Direito Oficial reconhece, tolera ou nega" (GRIFFITHS in FOBLETS, 89). Para ela, existe pluralismo jurídico quando dentro de um campo social determinado podemos encontrar comportamentos relativos a mais de um só ordenamento jurídico ${ }^{33}$.

Assim, como é possível perceber, a perspectiva da moderna antropologia jurídica provoca verdadeira revolução na apreensão clássica do direito ou do fenômeno jurídico, seu aparato e mecanismos de aplicação. Ela rebaixa o modelo ocidental de direito, visto e pensado por muito tempo como a mais alta expressão do jurídico ao seu devido lugar de mera modalidade regional e historicamente datada de manifestação jurídica, ao mesmo tempo em que reconhece todas as demais expressões históricas e atuais de direito como igualmente jurídicas e contemporâneas, apenas diferentes. Assim, o espaço jurídico ocidental, leia-se oficial, posto e pensado como universal, não pode mais ser representado como uma gradação contínua de sociedades sem poder separado em direção ao Estado. Na verdade, trata-se de um espaço irredutivelmente descontínuo, como a análise do Direito na Sociedade da Informação buscará explicitar doravante.

\section{O DIREITO NA SOCIEDADE DA INFORMAÇÃO}

A concepção de sociedade da informação (pós-moderna ou pós-industrial) é compreendida "[...] como a contemporaneidade onde a informação, bem intangível, constitui-se no maior valor e é produto de esforço intelectual que não depende de qualquer base material. Nesse cenário, o poder é difuso e disperso" ${ }^{\text {"4 }}$. Eduardo Iamundo em brilhante síntese ao definir a sociedade da informação adjetiva-a de sociedade capitalista afluente em que sua predominância está estritamente ligada

\footnotetext{
33 BARBOSA, op cit., 2001, p. 49.

${ }^{34}$ Ibidem. 2012, p. 130-131.
} 
ao capital financeiro, à prestação de serviços e no conhecimento cientifico ou tecnológico ${ }^{35}$. E afirma:

O conhecimento e a informação adquirem na sociedade afluente profundo significado e tornam-se mercadorias muito valorizadas. É oportuno esclarecer que o conhecimento da esfera científica tem maior ou menor valor, conforme a tecnologia que pode ser produzida e vendida. Em outras palavras, quanto maior a possibilidade que um conhecimento científico tem de transformar-se em mercadoria consumível, maior será seu valor. Quanto mais preciosa a informação no sentido de fonte geradora de benefícios, maior o seu valor no mercado ${ }^{36}$.

Neste ponto é preciso atentar para o fenômeno da globalização, cuja relevância ocorre a partir de 1980 com as intensas modificações políticas e econômicas de então, com destaque na seara política para o desmembramento da União das Repúblicas Socialistas Soviéticas, a queda do muro de Berlim e a hegemonia dos Estados Unidos da América e a visão internacionalista da política das relações entre os Estados-nação. Na economia significou a hegemonia do capitalismo, precipuamente do mercado, enquanto parâmetro para as tomadas de decisões (intensificação da movimentação financeira e complexidade na produção), decisões estas ligadas às grandes corporações. Com as novas tecnologias da informação (intensas e aperfeiçoadas), as diretrizes para os procedimentos administrativos e financeiros são realizadas por programas de computadores, intensificando a sofisticação do processo burocrático (controle) na sociedade contemporânea. Outro aspecto da globalização é a cultura, isto é, a migração de usos e costumes e a imposição de certas práticas culturais ${ }^{37}$.

Tais transformações e a divulgação do avanço das ciências misturam certezas e incertezas com um resultado paradoxal: individualização e o questionamento da complexidade social. Isto torna difícil a coesão social, desacreditando os procedimentos jurídicos como factíveis para realizar o Direito. Leia-se, propicia uma crise de legitimidade das instituições. A sociedade da informação:

[...] realiza muito menos do que se propóe e frequentemente transmite informação ambivalente, manipulada e manipulável assim como, a globalização engloba muito menos pessoas e povos do que

\footnotetext{
$\overline{35}$ IAMUNDO, Eduardo. Sociologia e Antropologia do Direito. São Paulo: Saraiva, 2013, p. 132.

${ }^{36}$ Idem.

${ }^{37}$ Idem, p. 132-133.
} 
o discurso ufanista sobre ela pretende. A mercadoria vem antes, e neste mercado, a informação e o conhecimento também são produtos $^{38}$.

Avançando no discurso Marco Antonio Barbosa, citando José Eduardo Faria, pontua:

[...] os novos paradigmas exigem a busca de um Direito enquanto conjunto de regras em movimento e continuamente reformuladas, inclusive por forças extra-legislativas e extra-estatais. Desse modo o próprio objeto da Ciência Jurídica é deslocado, não se encontrando mais no conjunto de normas instituído em dogmas, mas, exatamente, nos próprios fatos sociais $[\ldots]^{39}$.

Assim, o Estado enquanto fonte primordial da norma e da resolução de conflitos, na sociedade da informação (e em um mundo globalizado), não sustenta mais tal status, caracterizado pela divisão, antagonismo social e variações culturais dos sujeitos envolvidos, portanto, o Direito na Sociedade da Informação liga-se essencialmente à ética e à responsabilidade ${ }^{40}$.

\section{CONSIDERAÇÕES FINAIS}

O direito estatal moderno, balizado na retórica (mobilização da potência argumentativa, lastreada na sequência e artefatos verbais ou não e socialmente aceitos), na burocracia (potência demonstrativa de conhecimento, regras formais e procedimentos organizados hierarquicamente) e na violência (ameaça ou força física) vem progressivamente a partir já do final do século XIX perdendo seu elemento retórico e expandindo os elementos burocráticos e violentos, dificultando, por conseguinte, a administração da própria justiça enquanto pacificador social, instalando, ademais, desconfiança na sociedade que prefere uma justiça mais célere, menos custosa, mais acessível e mais satisfativa. Prefere, na verdade, mais do que "justiça", nos termos em que é apreendida e apresentada na perspectiva estatal, que buscaria identificar inocente e culpado, encontrar solução para os seus problemas

\footnotetext{
${ }^{38}$ BARBOSA e SANTOS com base em DEMO. O direito na sociedade da informação e perspectivas para a sociedade do conhecimento. Direitos Fundamentais \& Justiça, ano 8, n. 28, jul./set. 2014, p. 88.

${ }^{39}$ BARBOSA, Marco Antonio. Pluralismo Jurídico na Sociedade da Informação. Direitos Fundamentais \& Justiça, ano 6, n. 20, jul./set. 2012, p. 132.

40 Idem.
} 
por meio da harmonização das partes, provocando o contentamento da comunidade com a decisão e com o fim da violência. Neste passo, os meios alternativos, cuja gênese é a mediação, descentralização e informalidade, complementam os modelos do Estado (judiciais e administrativos). Este último tipo (alternativo), chamado por Boaventura de Souza Santos de comunitário, emerge na sociedade da informação ou do conhecimento como forma orgânica de complementar o direito estatal posto.

A hipótese inicialmente formulada, portanto, confirmou-se, na medida em que o fenômeno "Reclame Aqui" vem se mostrando como de grande aceitação e uso enquanto canal de comunicação, exposição e solução de conflito. E ainda, como grande vitrine que expõe o comportamento dos fornecedores. Os mecanismos de solução de conflitos empregados, em grande medida, coincidem com aqueles empregados nos sistemas tradicionais de direito, como os das sociedades ameríndias que, antes do recurso à repressão ou a outros meios violentos e homogêneos de sanções, recorrem a modalidades de medidas informais, como as inibidoras. Apenas quando esgotadas estas é que se faz recurso às punitivas. As medidas inibidoras correspondem a procedimentos informais e podem até mesmo tomar as cores do ridículo e da exposição pública daquele que pratica a ação antissocial, reprovável, o que pode, exatamente em razão da exposição pública, levá-lo a se enquadrar ao respeito do que é socialmente valorizado, do que é ético.

A inclusão/exclusão em redes e a arquitetura das relações entre redes, graças às tecnologias da informação que operam à velocidade da luz, é que configuram os processos e as funções predominantes nas sociedades contemporâneas ${ }^{41}$. Essa realidade criou os espaços digitais de conversão onde pessoas com os mesmos interesses, sejam físicas ou jurídicas, discutem seus jogos de tensão, sendo que a Internet abriu novas possibilidades. Foi o meio que possibilitou a convergência das pessoas ou grupos na busca de seus interesses comuns, afetando profundamente a tradicional compreensão do significado de direito, que assim desloca-se do lugar identificado com o Estado para outro que remete antes ao comunitário, às relações intersubjetivas e intergrupais, bem como desses entre si e com o próprio Estado e com outras instituições, sejam nacionais, regionais ou internacionais, sem, contudo, permitir a possibilidade de identificação de um centro ou qualquer comando prevalente.

O "Reclame Aqui", nascido de uma necessidade pessoal, como se analisou, encontrou outras vozes, aliás, milhares ou milhões de vozes, insatisfeitas ou

${ }^{41}$ CASTELLS, Manuel. A Sociedade em rede: a era da informação, economia, sociedade e cultura. 6. ed. São Paulo: Paz e Terra, 1999, v. 1, p. 566. 
inseguras com o tratamento dispensado aos seus direitos enquanto consumidores, tornando-se um 'espaço' ou 'canal', com características nitidamente muito próximas a um 'tribunal'. Soluciona conflitos, protege futuras insurgências e abre espaço ao diálogo, trazendo à baila a observância da ética e da responsabilidade nas relações consumeristas. Ganhou tamanha visibilidade e expõe transparentemente a todos que queiram saber qual tem sido o comportamento de tal e qual fornecedor. Assim, consumidores acessam o site para, antecipadamente, conhecer a reputação e o comportamento do fornecedor e, em seguida, com conhecimento de causa, decidem se vão ou não com ele contratar. Desse modo, o "Reclame Aqui" passou a ser além de espaço de solução de conflitos entre fornecedor e consumidor por meio de mecanismos informais e criativos, também uma vitrine transparente que fornece ao consumidor todas as informações a ele úteis no sentido de poder bem conhecer o fornecedor e seu comportamento antes de com ele contratar.

A antropologia moderna e suas orientações auxiliaram na correção do desvirtuamento teórico que levou à supressão dos estudos jurídicos acadêmicos relativos à produção e ao funcionamento de modalidades de solução de controvérsias não estatais, por meio da identificação do fenômeno conhecido como pluralismo jurídico.

Conclui-se, pois, da observação e leitura contextualizada do fenômeno social "Reclame Aqui", voltado à solução dos conflitos entre fornecedores e consumidores e à observância dos direitos consumeristas pelas empresas das mais variadas vertentes, que referido fenômeno revela-se como um exemplo vivo dentro da sociedade da informação de prática do pluralismo jurídico. Isto, simplesmente porque a dinâmica encetada para a solução dos problemas tratados não se pauta no formalismo-monismo-jurídico-estatal. Os meios empregados para se chegar à satisfação das reclamações e anseios daqueles que recorrem ao "Reclame Aqui" são criativos, plurais, e tributários de fontes diversas, tais como a corrente teóricoantropológica do pluralismo jurídico reconhece e expõe. Exemplificam a admissão e a prática de um direito mais aceito e/ou mais negociado do que de um direito imposto. Assim, desafia a experiência jurídica ocidental, caracterizada pelo direito largamente codificado. Substitui tal representação pela ideia de direito na qual o acordo convencional das partes desponta como regra. Um direito mais flexível. Tal prática demonstra, também, que o Direito deve ser compreendido como algo maior do que as suas fontes formais. Confirma ainda a tendência da sociedade pós-moderna e da informação, na qual arranjos particulares assumem e desvelam o seu lugar 
no contexto da juridicidade, tendo como base a pluralidade das próprias relações sociais, a partir da admissão da multiplicidade de pertencimentos dos membros da coletividade e que são mais ou menos institucionalizados. Direito dinâmico no grande jogo de juridicidade, a partir de múltiplos centros de produção e sanção de uma mesma sociedade, frequentemente identificada como global.

\section{REFERÊNCIAS}

ÁGORA. 2015. Disponível em: < http://www.superpesquisa.com> . Acesso em: 18 dez. 2015.

ASSIS, Olney Queiroz; KÜMPEL, Vitor Frederico. Manual de Antropologia Jurídica. São Paulo: Saraiva, 2015.

BARBOSA, Marco Antonio; SANTOS, Marco Aurelio Moura dos. O direito na sociedade da informação e perspectivas para a sociedade do conhecimento. Direitos Fundamentais \& Justiça, ano 8, n. 28, jul./set. 2014, p. 82-99.

BARBOSA, Marco Antonio. Pluralismo Jurídico na Sociedade da Informação. Direitos Fundamentais \& Justiça, ano 6, n. 20, jul./set. 2012, p. 114-134.

BARBOSA, Marco Antonio. Direito Antropológico e Terra Indígenas no Brasil. São Paulo: Fapesp/Plêiade, 2001.

BOSCO, Tiago. Os bastidores do Reclame Aqui e o novo perfil do consumidor. 2013. Disponível em: < http://www.revistawide.com.br/e-commerce/bastidores-doreclameaqui $>$. Acesso em: $14 \mathrm{dez} .2015$.

CASTELLS, Manuel. A Sociedade em rede: a era da informação, economia, sociedade e cultura. 8. ed. São Paulo: Paz e Terra, v. 1, 2005.

CASTELLS, Manuel. A galáxia da internet: reflexões sobre a internet, os negócios e a sociedade. Trad. Maria Luiza X. de A. Borges. Rio de Janeiro: Ed. ZAHAR, 2003.

CRUZ, Marilia de Oliveira. Midiatização e relações de consumo: um estudo de caso sobre as interações dos discursos entre consumidores e empresas no site Reclame Aqui. 2013. Dissertação (mestrado em Comunicação) - Pontifícia Universidade 
Católica de Minas Gerais, Programa de Pós-Graduação Stricto sensu, Belo Horizonte, 2013. Disponível em: <http://www.biblioteca.pucminas.br/teses/Comunicacao CruzMO_1>. Acesso em: 05 dez. 2015.

FERRAZ JR, Tércio Sampaio. Introdução ao estudo do direito: técnica, decisão, dominação. 8. ed. São Paulo: Atlas, 2015.

GALINDO, Daniel; BASSETTO, Jefferson. As muitas vozes do consumidor contemporâneo ecoam na ágora virtual. In: INTERCOM - SOCIEDADE BRASILEIRA DE ESTUDOS INTERDISCIPLINARES DA COMUNICAÇÃO XXXIV CONGRESSO BRASILEIRO DE CIÊNCIAS DA COMUNICAÇÃO, Recife, PE. Anais eletrônicos... Disponível em: <http://www.danielgalindo.ppg.br/As\%20muitas\%20vozes\%20 do\%20consumidor\%20contemporaneo\%20ecoam\%20na\%20agora\%20virtual. pdf $>$. Acesso em: 11 nov. 2015.

GOMES, Helton Simões. Conexão à internet via smartphone dobra no Brasil diz Google. Disponível em: < http://g1.globo.com/tecnologia/noticia/2015/08/conexaointernet-smartphone-dobra-no-brasil-em-2015-diz-google.html $>$. Acesso em: 14 dez. 2015.

IAMUNDO, Eduardo. Sociologia e Antropologia do Direito. São Paulo: Saraiva, 2014.

LÉVI-STRAUSS, Claude. Anthropologie Structurale. Paris: Plon, 1974.

MANY use internet daily. 2015. Disponível em: <http://www.pewglobal. org/2015/03/19/internet-seen-as-positive-influence-on-education-but-negativeinfluence-on-morality-in-emerging-and-developing-nations/technologyreport-11/>. Acesso em: 15 dez. 2015.

MARQUES, Cláudia Lima. Contratos no Código de Defesa do Consumidor: o novo regime das relações contratuais. 5. ed. São Paulo: Revista dos Tribunais, 2006.

PAESANI, Liliana Minardi. Direito e Internet: liberdade de informação, privacidade e responsabilidade civil. $6^{a}$ ed. São Paulo: Atlas, 2013.

PÁGINA inicial - Reclame Aqui. 2015. Disponível em: < http://www.reclameaqui. com.br/>. Acesso em: 18 dez. 2015. 
PORTAL Reclame Aqui - Como funciona? 2015. Disponível em: <http://www. reclameaqui.com.br/como_funciona/o-que-e-o-reclame-aqui_7/>. Acesso em: 14 dez. 2015.

PORTAL Reclame Aqui - Selo RA1000. 2015. Disponível em: <http://www. reclameaqui.com.br/selo/> . Acesso em: 14 dez. 2015.

SANTOS, Boaventura de Souza. O discurso e o poder: ensaio sobre a sociologia da retórica jurídica. Porto Alegre: Fabris, 1988.

SILVA, Narjara Bárbara Xavier; PAIVA, Cláudio Cardoso. Comunicação Digital: Estudo do Site Reclame Aqui - Um novo meio convergente entre a empresa e o consumidor 2.0. Revista Eletrônica Temática, ano V, n. 12, Dez. 2009, p. 1-14. Disponível em: $<$ http://www.insite.pro.br/2009/dezembro/narjara_reclame_consumidor.pdf. $>$. Acesso em: 12 nov. 2015.

TEMPERINI, Alessandro. Trabalhar com Facebook? Entenda o que é e o que faz o profissional de Social Media. 2015. Disponível em: < http://papouniversitario. anhembi.br/2015/04/trabalhar-com-facebook-entenda-o-que-e-e-o-que-faz-oprofissional-de-social-media/> . Acesso em: 11 jan. 2016.

Recebido em: 31 de agosto de 2015 Aceito em: 20 de julbo de 2016 